\title{
Mechanism of a Volatile Organic Compound (6-Methyl-2-Heptanone) Emitted From Bacillus subtilis ZD01 Against Alternaria solani in Potato
}

\section{OPEN ACCESS}

Edited by:

Florence Fontaine,

Université de Reims

Champagne-Ardenne, France

Reviewed by:

Ana Vazquez,

Universidad Católica de Córdoba,

Argentina

Valeria Scala

Centro di Ricerca Difesa e

Sperimentazione (CREA-DC), Italy

*Correspondence:

Zhihui Yang

13933291416@163.com

Jiehua Zhu

zhujiehua356@126.com

Specialty section:

This article was submitted to Microbe and Virus Interactions with

Plants,

a section of the journal

Frontiers in Microbiology

Received: 03 November 2021

Accepted: 08 December 2021

Published: 13 January 2022

Citation:

Zhang D, Qiang R, Zhao J, Zhang J, Cheng J, Zhao D, Fan Y, Yang $Z$ and Zhu J (2022) Mechanism of a Volatile Organic Compound (6-Methyl-2-Heptanone) Emitted From Bacillus subtilis ZD01 Against

Alternaria solani in Potato.

Front. Microbiol. 12:808337. doi: 10.3389/fmicb.2021.808337

\section{Dai Zhang ${ }^{1}$, Ran Qiang ${ }^{1}$, Jing Zhao', Jinglin Zhang' ${ }^{2}$ Jianing Cheng ${ }^{3}$, Dongmei Zhao',} Yaning Fan ${ }^{1}$, Zhihui Yang ${ }^{1 *}$ and Jiehua Zhu ${ }^{1 *}$

${ }^{1}$ College of Plant Protection, Hebei Agricultural University, Baoding, China, ${ }^{2}$ Beijing Laboratory for Food Quality and Safety, Beijing Technology and Business University, Beijing, China, ${ }^{3}$ Agricultural Business Training and Entrepreneurship Center, Hebei Agricultural University, Baoding, China

The antagonistic mechanisms of soluble non-volatile bioactive compounds, such as proteins and lipopeptides emitted from Bacillus have been widely studied. However, there are limited studies on the antifungal mechanisms of volatile organic compounds (VOCs) produced by Bacillus against plant fungal diseases. In this study, the antagonistic mechanisms of one specific VOC, 6-methyl-2-heptanone, against Alternaria solani were investigated. To optimize the extraction conditions of headspace solid-phase microextraction, a 50/30- $\mu \mathrm{m}$ divinylbenzene/carboxen/polydimethylsiloxane fiber at $50^{\circ} \mathrm{C}$ for 40 min was used. For gas chromatography-mass spectrometry using a free fatty acid phase capillary column, 6-methyl-2-heptanone accounted for the highest content, at 22.27\%, of the total VOCs from Bacillus subtilis ZD01, which inhibited A. solani mycelial growth strongly in vitro. Therefore, 6-methyl-2-heptanone was selected as the main active chemical to elucidate the action mechanisms against A. solani. Scanning and transmission electron microscopy analyses revealed that after exposure to an $\mathrm{EC}_{50}$ dose of 6-methyl-2-heptanone, A. solani hyphal cells had a wide range of abnormalities. 6-Methyl-2-heptanone also caused the capture of cellular fluorescent green label and the release of adenosine triphosphate (ATP) from outer membranes $A$. solani cells, which may enhance 6-methyl-2-heptanone ability to reach the cytoplasmic membrane. In addition, 6-methyl-2-heptanone showed strong inhibitory effect on $A$. solani conidial germination. It also damaged conidial internal structures, with the treated group having collapsed shrunken small vesicles as observed by transmission electron microscopy. Because 6-methyl-2-heptanone showed strong effects on mycelial integrity and conidial structure, the expression levels of related pathogenic genes in A. solani treated with 6-methyl-2-heptanone were investigated. The qRT-PCR results showed that transcriptional expression levels of slt2 and wetA genes were strongly down-regulated after exposure to 6-methyl-2-heptanone. Finally, because identifying the functions of pathogenic genes will be important for the biological control of $A$. solani, the wet $A$ gene was identified as a conidia-associated gene that plays roles in regulating sporulation yield and conidial maturation. These findings provide further insights into the mechanisms of VOCs secreted by Bacillus against $A$. solani.

Keywords: Alternaria solani, Bacillus subtilis, 6-methyl-2-heptanone, antifungal activity, conidial genes 


\section{INTRODUCTION}

Potato early blight caused by Alternaria solani is a main factor in the death of potato leaves, and it results in substantial yield losses (Morgan et al., 2002; Pasche et al., 2007; Peters et al., 2008). Fungicides are the main effective methods of controlling potato early blight disease. However, because of increased fungal pathogen drug resistance, environmental pollution and human health risks induced by the abuse of chemical fungicides (Wang and Liu, 2007; Maachia et al., 2015), there is a greater need for alternative environmentally friendly effective methods to control fungal diseases of potato.

Biological control has been widely regarded as a potential substitute for chemical fungicides owing to its environmental safety and high efficiency. The use of Bacillus strains as the biocontrol microorganisms is presently a promising strategy for controlling plant pathogens (Chaurasia et al., 2005; Zheng et al., 2013). Bacillus strains exhibit significant antifungal activities against various pathogenic fungi, such as Penicillium digitatum, Monilinia fructicola, and Botrytis cinerea (Wichitra et al., 2008; Senthil et al., 2011; Banani et al., 2015; Maachia et al., 2015; Liu et al., 2018). Recently, the use of volatile organic compounds (VOCs) produced by Bacillus strains was proposed as an alternative control method for plant fungal diseases (Chen et al., 2008; Gao et al., 2017; Haiyan et al., 2018; Massawe et al., 2018; Zhang X. Y. et al., 2020) because of their strong inhibitory effects on plant fungi (Chaves-López et al., 2015; Raza et al., 2016a,b; Gotor-Vila et al., 2017; Calvo et al., 2020). In addition, various VOCs produced by Bacillus strains have been identified as effective compounds (e.g., 2-nonanone, 2-methylpyrazine, and benzothiazole) (Arrebola et al., 2010; Raza et al., 2015; Khan et al., 2018; Liu et al., 2018; Xie et al., 2018; Wu et al., 2019; Calvo et al., 2020).

Recent research on the VOCs produced by Bacillus strains has primarily focused on evaluating volatile mixture biocontrol effects, including disease incidences in inoculated plants, spore germination, mycelial growth inhibition, and reduced sporulation, as well as the identification of exact VOC components (Kai et al., 2009; Schreinemachers and Tipraqsa, 2012; Khan et al., 2018; Tran et al., 2020). However, little is known about the biocontrol effects of specific identified VOC compounds. Moreover, the VOC types secreted by Bacillus strains are varied, including aldehydes, ketones, alcohols, and esters (Morath et al., 2012; Chantal et al., 2014). Additionally, different volatile chemicals do not have the same effects on, or the same degree of inhibition against, all fungi. This may be because different fungi respond to different component(s) of the volatile mixture and have different sites of action (Kai et al., 2009). For example, 3-methyl-1-butanol inhibits the mycelial growth of Fusarium oxysporum $\mathrm{f}$. sp. lactucae but has no antifungal activity against A. alternata and B. cinerea (Chaves-López et al., 2015). Therefore, it is essential to study the biocontrol functions of Bacillus-specific volatiles to further determine the action modes of VOCs secreted by Bacillus on fungal pathogens.

In our previous study, VOCs secreted by $B$. subtilis ZD01 exhibited significant antifungal activity against $A$. solani (Zhang D. et al., 2020). In this study, we discovered that 6-methyl-2-heptanone was the dominant component in the VOCs, and it also shows strong antagonistic effects against A. solani (Zhang D. et al., 2020). Therefore, we speculated that 6methyl-2-heptanone plays the most important role in pathogen inhibition. Consequently, we investigated the inhibitory effects of 6-methyl-2-heptanone produced by B. subtilis strain ZD01 on A. solani. Moreover, we identified the function of the wetA gene in A. solani. The results increase our knowledge of bacterial and fungal interactions mediated by VOCs and provide a potential strategy for potato early blight disease control.

\section{RESULTS}

\section{Optimization of Extraction Conditions and Identification of Volatile Organic Compounds Produced by $B$. subtilis ZD01}

Different extraction conditions for headspace solid-phase microextraction (HS-SPME) affect the extracting efficiency. Moreover, columns with different polarities also affect gas chromatography-mass spectrometry (GC-MS) analyses. In this study, the effects of extraction fibers, time, and temperature conditions on the HS-SPME of VOCs produced by B. subtilis ZD01 were evaluated, and a free fatty acid phase (FFAP) capillary column $(60 \mathrm{~m} \times 0.25 \mathrm{~mm} \times 0.25 \mu \mathrm{m})$ was used for GC-MS analyses of the produced volatiles. The total number of compounds and peak areas of the VOCs were used as the evaluation index.

Three kinds of extraction fibers $[85-\mu \mathrm{m}$ polyacrylate, 50/30- $\mu \mathrm{m}$ divinylbenzene/carboxen/polydimethylsiloxane (DVB/CAR/PDMS) and $75-\mu \mathrm{m}$ CAR/PDMS] were tested. The $85-\mu \mathrm{m}$ polyacrylate, $75-\mu \mathrm{m}$ CAR/PDMS, and $50 / 30-\mu \mathrm{m}$ DVB/CAR/PDMS fibers allowed GC-MS resolutions of 14, 13, and 19 distinct VOCs, respectively. In addition, a larger total peak area for the VOCs was obtained using $50 / 30-\mu \mathrm{m}$ $\mathrm{DVB} / \mathrm{CAR} / \mathrm{PDMS}$ compared with the other extraction fibers (Figure 1A). Thus, the use of $50 / 30-\mu \mathrm{m}$ DVB/CAR/PDMS increased the number and contents of VOCs. Consequently, we chose $50 / 30-\mu \mathrm{m} \mathrm{DVB} / \mathrm{CAR} / \mathrm{PDMS}$ as the extraction fiber for the following experiments.

The effect of extraction temperature on the GC-MS characterization of VOCs was analyzed. As shown in Figure 1B, $15,19,25$, and 22, total compounds were detected by GC-MS at extraction temperatures of $30,40,50$, and $60^{\circ} \mathrm{C}$, respectively. In addition, the peak area of the total compounds was greatest at $50^{\circ} \mathrm{C}$. Compared with other extraction temperatures, at $50^{\circ} \mathrm{C}$ the numbers and peak area of the total compounds detected by GC-MS were increased obviously. Thus, $50^{\circ} \mathrm{C}$ was selected as the extraction temperature.

We also evaluated the potential influence of extraction time on the GC-MS analysis of VOCs using 50/30- $\mu \mathrm{m} \mathrm{DVB/CAR/PDMS}$ at $50^{\circ} \mathrm{C}$. The extraction times of $20,30,40$, and 50 min allowed GC-MS identification of 19, 24, 25, and 27 VOCs, respectively. In addition, the peak area of the total compounds was maximum at $40 \mathrm{~min}$, which was much greater than at the other time 

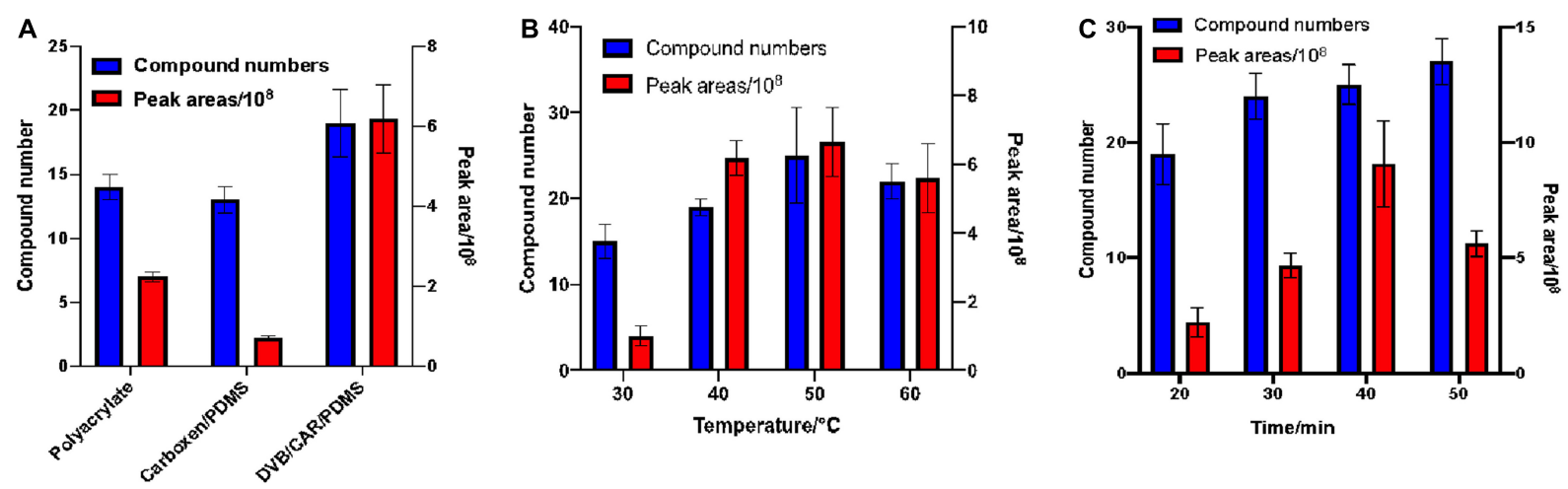

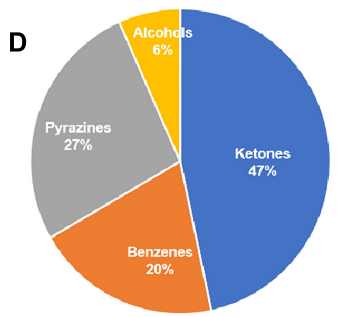

Total=15

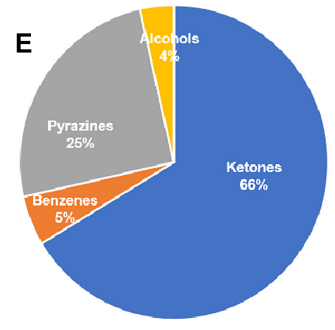

Total $=100 \%$

FIGURE 1 | Optimization of collection conditions with HP-SPME for the GC-MS determination of VOCs. The effects of extraction fibers, time, and temperature on HS-SPME results for VOCs produced by B. subtilis ZD01 were evaluated. Total number of compounds and peak areas of VOCs served as the evaluation index. (A) Extraction fibers. (B) Extraction temperature. (C) Extraction time. After extraction, the analytes were identified by GC-MS. The compounds were classified into different classes based on their structures and functional groups, and we calculated the total peak areas of each of the four classes. (D) Classification of VOCs produced by ZD01. (E) Peak areas of four identified classes of VOCs from ZD01. The results are presented as the means \pm SDs $(n=3)$.

points (Figure 1C). Therefore, we selected to use the $50 / 30-\mu \mathrm{m}$ $\mathrm{DVB} / \mathrm{CAR} / \mathrm{PDMS}$ fiber at $50^{\circ} \mathrm{C}$ for $40 \mathrm{~min}$ as the extraction conditions for GC-MS.

Gas chromatography-mass spectrometry with a FFAP capillary column $(60 \mathrm{~m} \times 0.25 \mathrm{~mm} \times 0.25 \mu \mathrm{m})$ was used to detect the volatiles of ZD01 samples and control samples (LuriaBertani medium alone) under optimized extraction conditions (50/30 $\mu \mathrm{m} \mathrm{DVB/CAR/PDMS} \mathrm{fiber} \mathrm{at} 50^{\circ} \mathrm{C}$ with $40 \mathrm{~min}$ ). LB medium without Bacillus inoculation was used as a control. Identical volatile compounds produced by ZD01 and LB medium were eliminated. In total, 15 volatiles specifically released by ZD01 were obtained, including 7 ketones, 4 pyrazines, 3 benzenes, and 1 alcohol (Figures 1D,E and Table 1). Among them, 6-methyl-2-heptanone showed the largest peak area, at $22.27 \%$ of the total VOCs. Moreover, 6-methyl-2-heptanone was identified as having an $8.88 \%$ peak area of the total VOCs by GC-MS using an HP-5 capillary column and has shown strong antagonistic effects on A. solani (Zhang D. et al., 2020). Therefore, 6-methyl-2-heptanone may be the main active chemical; therefore, it was selected as a potential agent for controlling potato early blight.

\section{6-Methyl-2-Heptanone Inhibited Mycelial Growth and Induced Structural Changes in $A$. solani in vitro}

Because 6-methyl-2-heptanone may be a potential agent for controlling potato early blight, pure 6-methyl-2-heptanone purchased from a company was tested for antifungal activity. In detail, divided dishes were used to evaluate the inhibition of 6-methyl-2-heptanone against $A$. solani mycelial growth and its pathogenicity. 6-Methyl-2-heptanone suppressed mycelial growth by more than $78 \%$ at its highest dose $(15 \mu \mathrm{L})$ (Figure 2A). For this compound, an $\mathrm{EC}_{50}$ value of $10.88 \mu \mathrm{L}$ was obtained.

Mycelial structures play vital roles in the infection process, and they form a special structure, the penetration peg, before invading plant leaves. Thus, we evaluated the potential effects of 6-methyl2-heptanone on A. solani mycelial ultrastructures. Scanning electron microscopy (SEM) was used to study the surface morphological changes of A. solani. As shown in Figure 2B, the control hyphae had smooth surfaces and intact morphology. In contrast, some 6-methyl-2-heptanone-treated hyphae had wrinkled surface cells (red arrows, Figure 2B). Hyphae exhibited swelling tissues on the surface (yellow arrows, Figure 2B) after exposure to 6-methyl-2-heptanone. Moreover, compared with normal hyphae, some of the A. solani 6-methyl-2-heptanonetreated mycelia were deformed and significantly enlarged (green arrows, Figure 2B).

Because the 6-methyl-2-heptanone-treated A. solani hyphae showed serious surface structure abnormalities, their internal structure used transmission electron microscopy (TEM). As shown in Figure 2C, in cross-sections, hyphae from control groups were elliptical-shaped with a clear outer cell-wall edge, cytoplasmic membrane and uniform periplasmic space. The cytoplasm was evenly distributed, with a consistent electron 
TABLE 1 | Volatile compounds produced by Bacillus subtilis ZD01 identified under optimal conditions using an free fatty acid phase (FFAP) chromatographic column.

\begin{tabular}{|c|c|c|c|c|c|c|}
\hline No. & Chemicals & CAS & Retaining time (min) & SI & RSI & Peak area ratio (\%) \\
\hline 1 & 3-Methyl-2-pentanone & $565-61-7$ & 7.27 & 863 & 913 & 3.32 \\
\hline 2 & 2-Heptanone & $110-43-0$ & 10.22 & 867 & 877 & 4.42 \\
\hline 3 & 6-Methyl-2-heptanone & $928-68-7$ & 11.46 & 888 & 892 & 22.27 \\
\hline 4 & 5-Methyl-2-heptanone & $18217-12-4$ & 11.90 & 855 & 858 & 19.08 \\
\hline 5 & Methyl-pyrazine & $109-08-0$ & 12.41 & 939 & 941 & 6.65 \\
\hline 6 & 2,5-Dimethylpyrazine & $123-32-0$ & 13.73 & 944 & 946 & 12.47 \\
\hline 7 & 6-Methyl-2-heptanol & $4730-22-7$ & 14.58 & 874 & 885 & 3.53 \\
\hline 8 & 2-Ethyl-5-methyl-pyrazine & $13360-64-0$ & 15.20 & 687 & 826 & 3.87 \\
\hline 9 & 2-Methyl-5-(1-methylethyl)pyrazine & $13925-05-8$ & 15.81 & 845 & 975 & 2.00 \\
\hline 10 & 2-Decanone & $693-54-9$ & 16.59 & 821 & 871 & 10.77 \\
\hline 11 & Acetophenone & $98-86-2$ & 21.90 & 639 & 863 & 4.70 \\
\hline 12 & 2-Ethyl-6-methyl-phenol & $1687-64-5$ & 26.59 & 693 & 871 & 3.24 \\
\hline 13 & Phenylethyl alcohol & $60-12-8$ & 27.44 & 688 & 882 & 1.34 \\
\hline 14 & 1,2-Benzisothiazole & $272-16-2$ & 28.63 & 772 & 922 & 0.53 \\
\hline 15 & 2-Nonadecanone & $629-66-3$ & 30.45 & 731 & 869 & 1.81 \\
\hline
\end{tabular}

SI, strength indexes; RSI, relative strength indexes.

A

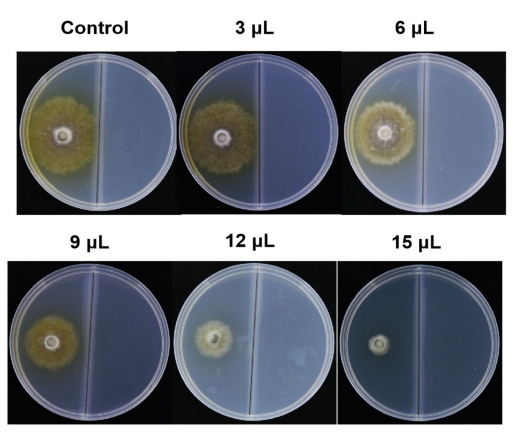

C

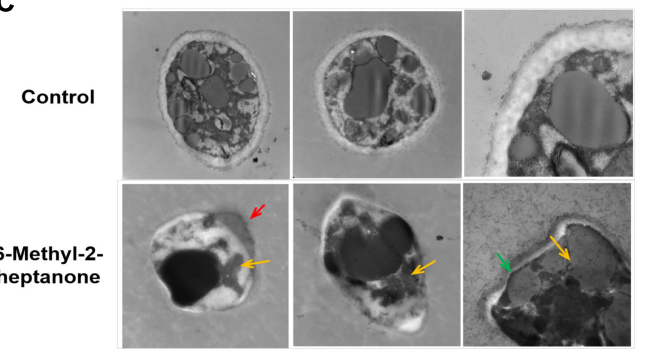

B
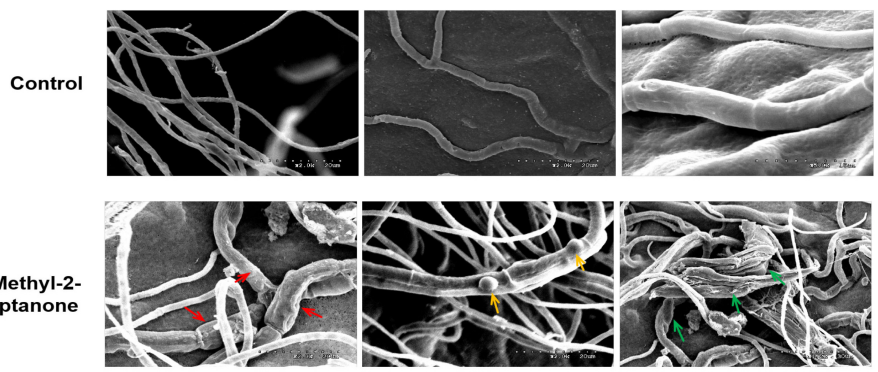

D

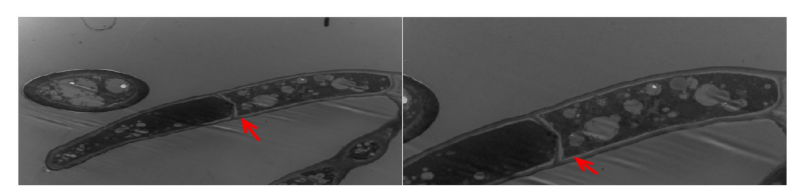

6-Methyl-2-

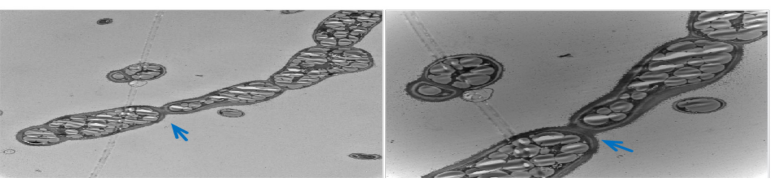

FIGURE 2 | Mycelial growth of A. solani after the 6-methyl-2-heptanone treatment in vitro. A 5-mm square plug of an A. solani mycelial agar disc was placed in one compartment of the divided plate containing PDA medium, and the other compartment containing PDA medium was incubated with different aliquots of pure 6-methyl-2-heptanone. (A) Antagonistic effects of five different doses (3, 6, 9, 12, and $15 \mu \mathrm{L})$ of 6-methyl-2-heptanone against $A$. solani mycelia. (B) Scanning electron micrographs of $A$. solani co-cultured with 6-methyl-2-heptanone. The "red arrows" represented wrinkled surface cells of hyphae treated with 6-methyl-2-heptanone; the "yellow arrows" represented swelling tissues on the surface of hyphae after exposure to 6-methyl-2-heptanone; "green arrows" represented 6-methyl-2-heptanone-treated mycelia deformed and significantly enlarged. (C, D). Transmission electron micrographs of $A$. solani hyphae co-cultured with 6-methyl-2-heptanone. The "green arrows" represented thinner cell walls; "red arrows" represented the movement of the cytoplasmic content towards the ruptured cell walls or cytoplasmic membranes; "yellow arrows" represented shrunken cytoplasm and decreased number of inclusions in Figure 2C. The "red arrows" represented clear septa in hyphae from the control groups; the "blue arrows" represented hyphae with wrinkled obviously at the septa after exposure to 6-methyl-2-heptanone in Figure 2D.

density. Nuclei, vacuoles, and mitochondria were also distributed randomly in the cells (Figure $2 \mathrm{C}$ ). Compared with the undamaged control cells, a wide range of misshapen and severely deformed cells were observed in treated A. solani. Cell walls were thinner (green arrows, Figure 2C) and even damaged (red arrows, Figure 2C), which resulted in the movement of the cytoplasmic content toward the ruptured cell walls or cytoplasmic membranes (red arrow, Figure 2C). The cytoplasm 
A
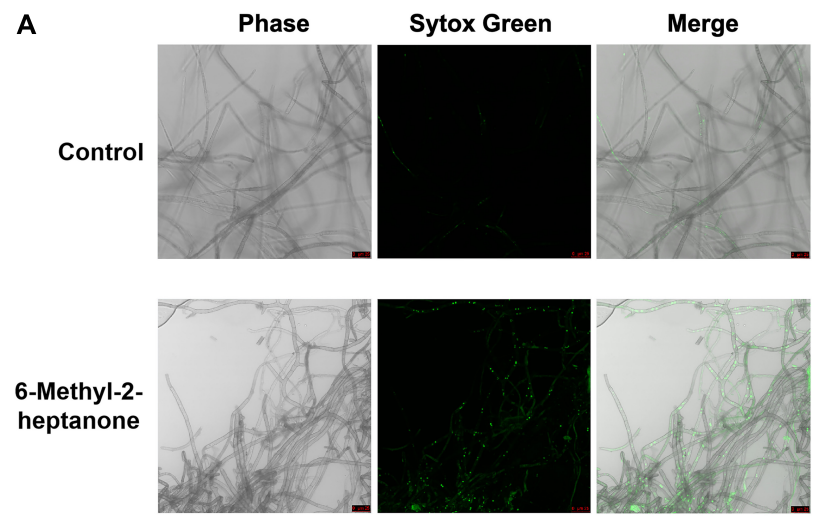

B

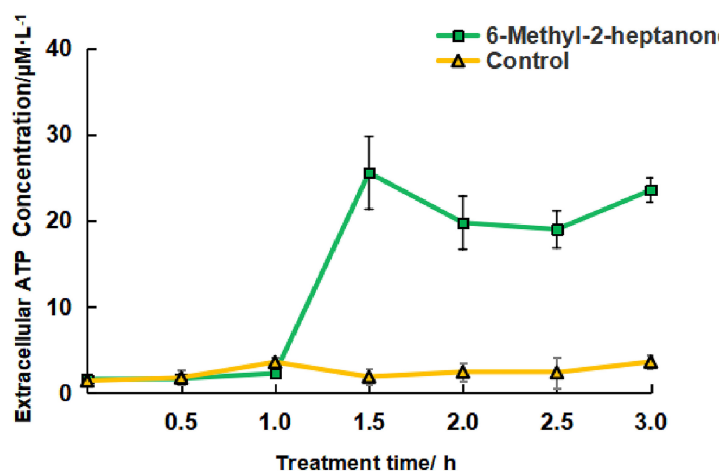

FIGURE 3 | Effects of 6-methyl-2-heptanone on the cell-membrane permeability of $A$. solani hyphae. (A) Fluorescence microscopy imaging of $A$. solani hyphae treated with 6-methyl-2-heptanone and a control group. Membrane permeability changes in A. solani mycelial cells were detected using SYTOX Green dye after a 6-h incubation with an EC $_{50}$ value of 6-methyl-2-heptanone. Green fluorescence illumination in treated samples signifies membrane damage in fungal cells. The phase channel showed all fungal cells on bright-field images, and the SYTOX Green channel showed cells attached or inserted with SYTOX Green labeled; the merge channel showed the proportion of SYTOX Green-labeled cells. (B) Effects of 6-methyl-2-heptanone on ATP release from A. solani. The changes in the extracellular ATP levels of $A$. solani represent cell-membrane damage. The ATP level was measured using an ATP kit based on a luminescent ATP assay and is presented in relative light units. The results are presented as the means $\pm \operatorname{SDs}(n=3)$.

was shrunken, and the number of inclusions decreased (yellow arrows, Figure 2C). Longitudinal sections of hyphae from the control groups were normal size with similar width and had clear septa (red arrows, Figure 2D). However, in the treated group, the mycelia were inflated. Many hyphae also appeared wrinkled obviously at the septa after exposure to 6-methyl-2heptanone (blue arrows, Figure 2D). Moreover, more and larger lipid droplets were observed in the cytoplasm of treated samples compared with the control groups, which had only a few dark internal lipid droplets (Figures 2C,D).

\section{The Cell-Membrane Permeability of A. solani Hyphae Changed After the 6-Methyl-2-Heptanone Treatment}

To further identify the mechanisms by which 6-methyl-2heptanone produces the antifungal activity against $A$. solani hyphal cells, we used SYTOX Green labeling to detect the membrane permeability. As shown in Figure 3A, none of the cells fluorescent green in the control group. In contrast, some cells fluorescent green in samples that had been exposed in the $\mathrm{EC}_{50}$ value of 6-methyl-2-heptanone for 4 days.

To further identify the damaging effects of 6-methyl-2heptanone on cell membranes, the adenosine triphosphate (ATP) contents released into the extra-cellular medium were used as an indicator of the effects of 6-methyl-2-heptanone on the membranes of fungal hyphae. As shown in Figure $3 \mathbf{B}$, the extracellular ATP level of A. solani rapidly increased after $1 \mathrm{~h}$ exposure to the $\mathrm{EC}_{50}$ value of 6-methyl-2-heptanone. In contrast, the extracellular ATP levels of the control cells were constantly low, from 0.5 to $3 \mathrm{~h}$, which suggested that 6-methyl-2-heptanone caused serious ATP leakage from A. solani hyphal cells. Thus, the results further indicated that 6-methyl-2-heptanone increased $A$. solani cell-membrane permeability.

\section{6-Methyl-2-Heptanone Inhibited Conidial Vitality and Damaged Internal Structures of $A$. solani Conidia}

In addition to mycelia, conidial vitality also plays a crucial role during the infection of fungal pathogens. Conidia resist severe environmental conditions and are spread by wind and rain. After adhering to potato leaves, conidia form penetration pegs, special mycelial structures, which infect potato leaves. Therefore, the capacity of 6-methyl-2-heptanone to suppress conidial vitality was evaluated in vitro. As shown in Figure $\mathbf{4 A}$, the germination rate of conidia treated with the $\mathrm{EC}_{50}$ value of 6-methyl-2-heptanone was $74.73 \% \pm 2.11 \%$, whereas it was $99.62 \% \pm 1.67 \%$ in the control group, which suggested that 6-methyl-2-heptanone inhibited A. solani conidial germination significantly $(p<0.05)$. Conidia in the control sample germinated normally and formed long germ tubes (black arrow, Figure 4B) to infect plants. However, conidia exposed to 6-methyl-2-heptanone formed irregular germ tubes (blue arrow, Figure 4B). This shorter tube did not have the ability to penetrate and invade host epidermal cell junctions.

Transmission electron microscopy was then used to detect the degree of damage to conidial structures. The majority of A. solani conidia treated with 6-methyl-2-heptanone showed severe morphological disruptions. Collapsed shrunken were detected. Additionally, more extracellular secretions occurred around the conidial cell-wall surface, and larger lipid droplets appeared within the conidia (Figures 4C,D). In the control group not exposed to 6-methyl-2-heptanone, conidia exhibited regular shapes, uniformly distributed cytoplasm and apparently intact envelopes. We also observed electron dense cytoplasm and robust ultra-structures in the control group (Figures 4C,D). The findings confirmed that 6-methyl-2-heptanone damaged conidial structures. 
A

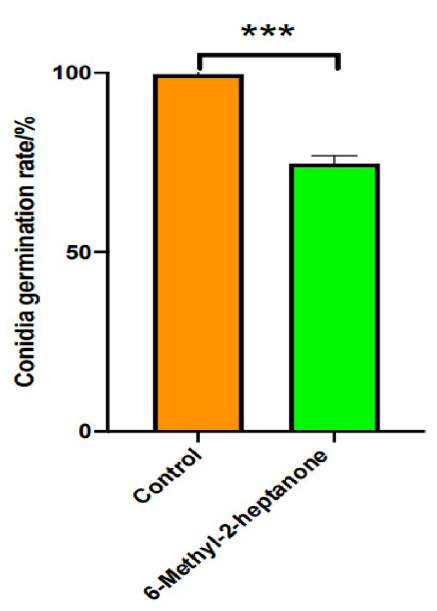

C

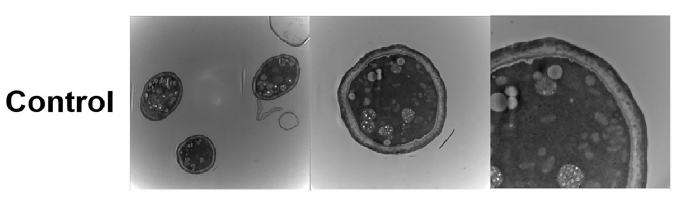

6-Methyl-2heptanone

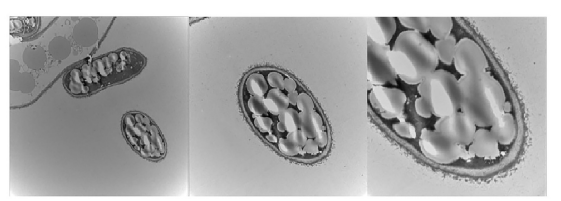

B

6-Methyl-2heptanone

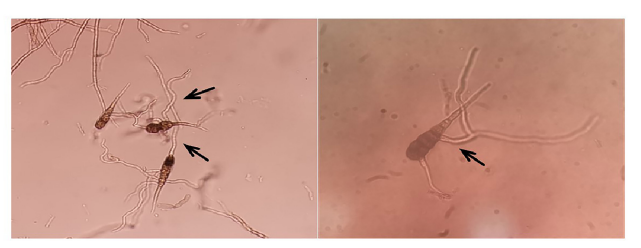

D

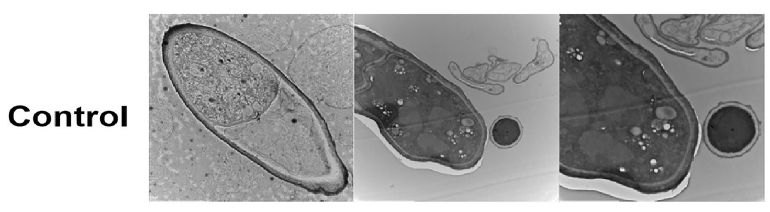

6-Methyl-2heptanone

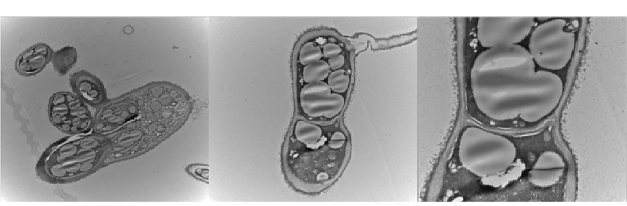

FIGURE 4 | Effects of 6-methyl-2-heptanone on conidia of $A$. solani. Here, $100 \mu \mathrm{L}$ of $A$. solani HWC-168 spore suspension (10 $\mathrm{cfu} / \mathrm{mL})$ was spread onto $1.0 \%$ water agar medium on a divided dish, and the other side of the dish was inoculated with an $\mathrm{EC}_{50}$ value of 6-methyl-2-heptanone. (A, B) The conidial germination of A. solani in the control and 6-methyl-2-heptanone-treated groups, respectively. The "black arrow" represented conidia germinating normally with long germ tubes in the control sample; the "blue arrow" represented conidia with irregular germ tubes exposed to 6-methyl-2-heptanone. (C, D) Transmission electron micrographs of A. solani conidia in control samples and co-cultured with 6-methyl-2-heptanone samples. The results are presented as the means \pm SDs $(n=3)$. ${ }^{\star \star \star}$ above points represent significant differences $(p<0.01)$.

\section{6-Methyl-2-Heptanone Downregulated the Expression of Pathogenic Genes in \\ A. solani}

Because 6-methyl-2-heptanone showed strong effects on mycelial integrity and conidial structures, we further investigated the action mode of 6-methyl-2-heptanone against $A$. solani by examining the expression levels of pathogenic mycelia- and conidia-related genes. In our previous study, we determined that the slt2 gene is involved in mycelial growth, penetration, and pathogenicity (Zhang D. et al., 2020). Moreover, fungi spread through spores, and conidia also play a key role in the A. solani infection process. The complete genome of A. solani HWC-168 has been sequenced and analyzed (Zhang et al., 2018), and one typical gene, wetA, related to conidia was found in the genome. Therefore, we investigated the effects of 6-methyl-2-heptanone transcription on the expression profiles of slt2 and wetA in A. solani using qRT-PCR.

After A. solani strain HWC-168 was exposed to 6-methyl-2heptanone for $2 \mathrm{~h}$ and $6 \mathrm{~h}$, the expression of wetA was strongly repressed (approximately 1.31- and 0.96-fold, respectively) (Figure 5A). The transcriptional expression of slt2 was induced (approximately 1.42-fold) compared with the control group and then repressed (approximately 0.61 -fold) in the presence of VOCs after 2- and 6-h co-culturing (Figure 5A). The downregulated expression levels of slt 2 and $w e t A$ were consistent with the virulence reduction in A. solani.

\section{WetA Is a Conidia-Associated Gene in}

\section{A. solani}

Identifying the functions of pathogenic genes is important for determining pathogenic mechanisms and biological control approaches for A. solani. Moreover, little is known about the functions of $A$. solani pathogenesis-related genes. Because 6-methyl-2-heptanone showed a strong effect on the transcriptional expression of wetA in conidia, we compared the wetA gene sequence in $A$. solani with those of 22 fungi. The wetA gene in A. solani is closely related to the wetA gene in Alternaria alternate (Supplementary Figure 1). Then, the functions of wetA were determined using gene knockouts and phenotype verification.

To determine whether wetA affects the pathogenicity of A. solani, the virulence of the deletion mutants and the wild-type 


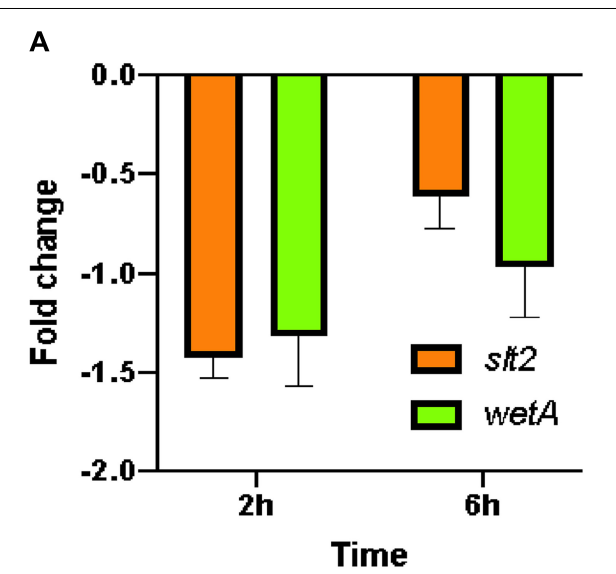

D
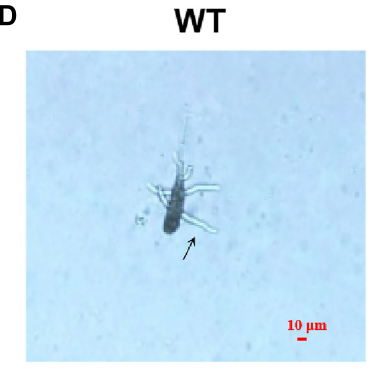

Time
B
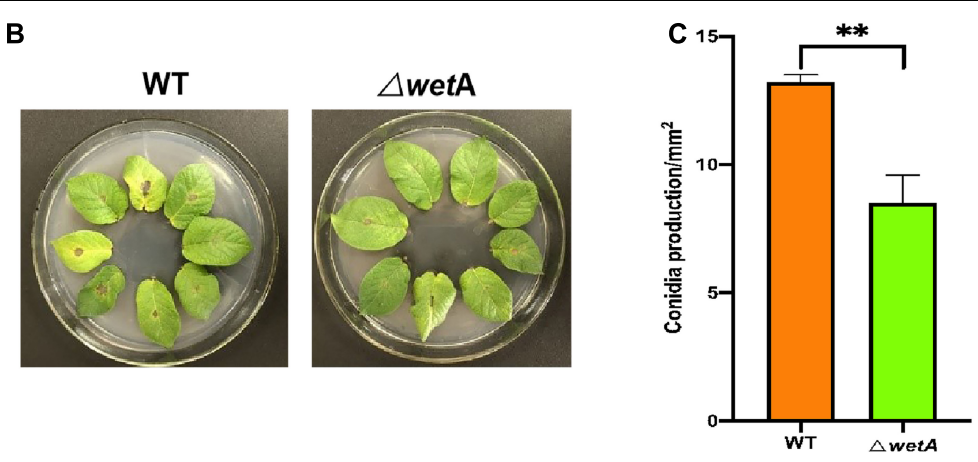

$$
\begin{aligned}
& \text { FIGURE } 5 \text { | WetA is key conidia-related gene in A. solani. (A) Transcriptional expression profiles of slt2 and wet } A \text { after co-culturing with } 6 \text {-methyl-2-heptanone for } 2 \\
& \text { and } 6 \text { h. (B) Symptoms of early blight disease on potato leaf caused by wild-type } A \text {. solani (WT) and mutants }(\Delta \text { wetA). (C) The sporulation yield of WT) and } \Delta \text { wetA). } \\
& \text { (D) The length of } \Delta \text { wetA mutant and WT germ tubes after a 2-h heat treatment. The "arrows" represented the lengths of } \Delta \text { wet } A \text { mutant and WT germ tubes. (E) } \\
& \text { Transmission electron micrographs of conidia of WT and } \Delta \text { wetA. The "arrows" represented C1 and C2 layers respectively; the "arrowheads" represented the width of } \\
& \text { conidial wall. The results are presented as the means } \pm \text { SDs }(n=3) .{ }^{\star \star} \text { above points represent significant differences }(p<0.05) \text {. }
\end{aligned}
$$

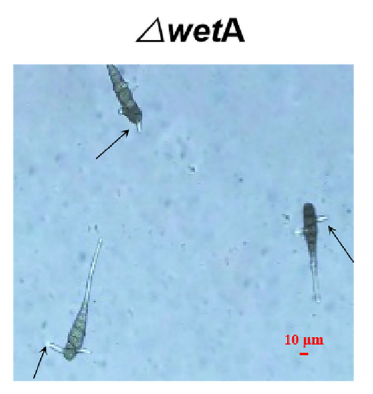

E

WT

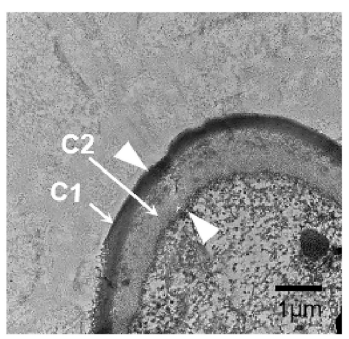

$\Delta$ wetA

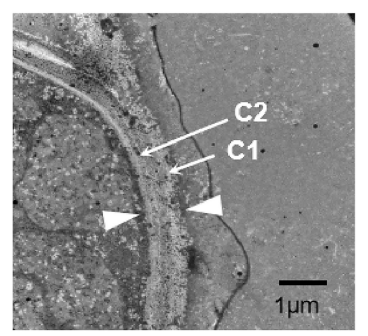

(WT) strain were compared in vivo using potato leaf tests. As shown in Figure 5B, potato leaves inoculated with WT HWC-168 showed obvious lesions and yellow halos. The lesion diameters extended to $0.50 \pm 0.07 \mathrm{~cm}$ after a 7 -day incubation at $25^{\circ} \mathrm{C}$, whereas for the leaves inoculated with $\Delta$ wet $A$ mutants, the lesion diameters were limited to $0.20 \pm 0.06 \mathrm{~cm}$. Thus, the deletion of wetA significantly reduced the pathogenicity of $A$. solani $(p<0.05)$.

Then, we evaluated the sporulation and conidia germination of deletion mutants and the WT strain under in vitro conditions. As shown in Figure 5C, the sporulation yield of the wetA deletion mutant per area was $8.51 \pm 1.09 \times 10^{2} / \mathrm{mm}^{2}$, whereas that of the WT strain was $13.21 \pm 0.28 \times 10^{2} / \mathrm{mm}^{2}$. Compared with the WT strain, the sporulation yield of the wetA deletion mutant per area decreased significantly $(p<0.05)$. These results suggested that wetA has a significant role in sporulation. Moreover, we examined the conidial germination of WT A. solani and mutants $(\triangle$ wet $A)$ after a 2 -h heat treatment. The conidial germination of WT was $40.67 \% \pm 2.52 \%$, whereas that of the $\Delta$ wetA mutants was limited to $27.33 \% \pm 1.17 \%$. The lengths of $\Delta$ wetA mutant and WT germ tubes were $18.56 \pm 2.89 \mu \mathrm{m}$ and $57.96 \pm 4.90 \mu \mathrm{m}$, respectively (Figure 5D). The results indicated that expression of the wet $A$ gene had strong inhibitory effects on conidial germination and germ tube elongation under heat-treatment conditions.
To examine the role of wetA in conidial vitality, WT and wetA mutant conidia in A. solani were compared using TEM. As shown in Figure 5E, WT conidia formed a crenulated electrondense $\mathrm{C} 1$ layer and a condensed electron-light $\mathrm{C} 2$ layer. In the wet $A$ mutants, although the $\mathrm{C} 1$ and $\mathrm{C} 2$ layers were formed, the $\mathrm{C} 1$ layer was not crenulated and the $\mathrm{C} 2$ layer failed to condense, resulting in a thicker conidial wall than in the WT strain. Moreover, the $\mathrm{C} 1$ layer was subtended by projections from the C2 layer in the WT strain, and this was not observed in the wetA mutant strain. These data indicated that the wetA mutant exhibits conidial wall defects similar to those found in Aspergillus nidulans (Sewall et al., 1990; Marshall and Timberlake, 1991) and that wetA plays an essential role in conidial wall completion and spore maturation.

\section{DISCUSSION}

Mycelial growth, hyphal morphology, and conidial germination are significant factors in the plant infection processes of fungal pathogens. Consequently, most previous studies focused on plant fungal mycelial morphology and spore germination after being treated with VOC mixtures emitted by bacterial strains (Chaurasia et al., 2005; Effmert et al., 2012; Morath et al., 2012; Zheng et al., 2013; Chantal et al., 2014; Xie et al., 2018; Li et al., 
2019; Martins et al., 2019; Wu et al., 2019; Tran et al., 2020). For example, the VOCs of Bacillus velezensis 5YN8 suppress the mycelial growth and conidial formation of B. cinerea BC1301 (Jiang et al., 2018). Excessive vesication or thickened cell walls in conidia and increased plasma membrane retractions have been observed by TEM in mycelia of $B$. cinerea fumigated with Bacillus VOCs (Li et al., 2012). In our previous study, we also found that volatiles secreted by the ZD01 strain inhibit mycelial growth and conidial germination (Zhang D. et al., 2020). Thus, most of studies have focused on the effects of volatile mixtures produced by Bacillus stains against plant fungi. However, the action sites of different component(s) of the volatile mixtures may vary in different fungi, and little is known about the action mechanisms of specific effective substances in VOCs on plant pathogens.

In our study, 6-methyl-2-heptanone accounted for relatively large contents, at 22.27 and $8.88 \%$ of the total VOCs from B. subtilis ZD01, using FFAP and HP-5 capillary columns, respectively, in GC-MS analyses, and it inhibited $A$. solani mycelial growth strongly in vitro (Zhang D. et al., 2020). Furthermore, 6-methyl-2-heptanone is produced by Bacillus strains and shows significant antifungal activities against plant pathogens. For example, 6-methyl-2-heptanone produced by Bacillus vallismortis $12 \mathrm{a}$ and Bacillus altitudinis $14 \mathrm{~b}$ completely inhibits the mycelial growth of Monilinia fructicola (Liu et al., 2018). Therefore, 6-methyl-2-heptanone may be a key active chemical component of VOCs emitted from Bacillus strains that can be used for controlling plant disease. Consequently, we selected it as a specific effective substance to elucidate the action mechanisms against $A$. solani. We found that 6 methyl-2-heptanone damaged cell-wall integrity and changed cell-membrane permeability. Cell walls and membranes are crucial for maintaining cell viability (Bowman and Free, 2006; Ruiz-Herrera et al., 2006; Shao et al., 2013; Tao et al., 2014). It is, therefore, necessary to reveal the interactions of bioactive VOCs with model membranes.

Currently, little is known about the functions of $A$. solani pathogenesis-related genes, which may be important for the biological control of plant pathogens. In this study, the function of the wetA gene, which is involved in conidial vitality in A. solani, was identified using a constructed knockout mutant and phenotypical characterization. The wet $A$ mutant strain failed to form condensed C1 and C2 layers, which was consistent with previous studies (Sewall et al., 1990; Marshall and Timberlake, 1991). In $A$. nidulans, the wet $A$ gene is required late in development for the synthesis of crucial cell-wall layers (Marshall and Timberlake, 1991). The inner wall layer of wetA mutant conidia did not condense during Stage II, and they form large cytoplasmic vacuoles that undergo lysis (Sewall et al., 1990). Here, the WT C1 layer was slightly more crenulated than that of the $\Delta$ wet $A$ strain. The $\mathrm{C} 2$ layer appears condensed in the WT but not in the wet $A$ mutant strain (Sewall et al., 1990). Therefore, wet $A$ plays crucial roles in the sporulation and conidial wall formation of A. solani, which had further effects on its pathogenicity in in vivo tests.

In summary, this study first elucidated the action mechanism of B. subtilis ZD01 metabolite 6-methyl-2-heptanone to control A. solani and shed light on the potential biocontrol mechanism of 6-methyl-2-heptanone against A. solani in potato (Figure 6). 6-Methyl-2-heptanone caused hyphal deformity and damaged the cell integrity and membrane permeability of A. solani hyphae, which could not form the penetration pegs. Additionally, it inhibited conidial germination and altered conidial structures. Moreover, 6-methyl-2-heptanone downregulated the transcriptional expression levels of slt 2 and wetA genes, which are involved in mycelial vitality, sporulation, and conidial maturity. Future research will focus on increasing the safety of 6-methyl-2-heptanone treatments and determining the action sites of 6-methyl-2-heptanone produced by B. subtilis ZD01 against $A$. solani.

\section{EXPERIMENTAL PROCEDURES}

\section{Optimization of Volatile Organic Compound Collection Conditions}

Here, $20 \mu \mathrm{L}$ of Bacillus strain suspension $\left(1 \times 10^{8} \mathrm{cfu} / \mathrm{mL}\right)$ was inoculated into $6 \mathrm{~mL} \mathrm{LB}$ medium in a $20-\mathrm{mL}$ headspace-vial. The vials were firmly sealed using parafilm and rubber lids, and then, they were incubated at $25^{\circ} \mathrm{C}$ for 4 days before VOC collection. HS-SPME and GC-MS were used to analyze the samples.

A SPME holder from Supelco, Inc. (Bellefonte, PA, United States) was used to perform HS-SPME manually. The SPME fibers were also purchased from Supelco, Inc. The extraction conditions were optimized in accordance with a previous method (Zhang et al., 2021). Briefly, the vials were water-bathed in a heated metal block with the SPME fiber inserted in the headspaces under different extraction conditions for optimization. We used the extraction fiber, temperature, and time as factors. We chose $85-\mu \mathrm{m}$ Polyacrylate, $75-\mu \mathrm{m}$ Carboxen/PDMS, and 50/30- $\mu \mathrm{m}$ DVB/CAR/PDMS as the extraction fibers for optimization at $40^{\circ} \mathrm{C}$ condition for $40 \mathrm{~min}$. Next, the extraction temperature was optimized using the optimal fiber for $40 \mathrm{~min}$ at $30,40,50$, and $60^{\circ} \mathrm{C}$. To optimize the extraction time, the VOCs were extracted for $20,30,40$, and $50 \mathrm{~min}$ with the optimized fiber and temperature. Finally, the VOCs were extracted using the optimized conditions. The experiment was repeated three times. All the strains used in this study are listed in Supplementary Table 1.

\section{Analysis of Volatile Organic Compounds From B. subtilis ZD01 by Gas Chromatography-Mass Spectrometry}

After extraction, the analytes were desorbed for $5 \mathrm{~min}$ at $250^{\circ} \mathrm{C}$ in the injector of the GC with the purge valve off (split-less mode). Capillary GC-MS was carried out using a Thermo Trace 1310 gas chromatographer (Thermo Fisher Scientific, Waltham, MA, United States). The samples were analyzed on a FFAP capillary column $(60 \mathrm{~m} \times 0.25 \mathrm{~mm} \times 0.25 \mu \mathrm{m}$, Thermo Fisher Scientific). The temperature of the injection port was $230^{\circ} \mathrm{C}$. The flow rate was $1 \mathrm{~mL} / \mathrm{min}$. We used the following temperature program: start at $50^{\circ} \mathrm{C}$; increase to $220^{\circ} \mathrm{C}$ at $5^{\circ} \mathrm{C} / \mathrm{min}$; and hold at $220^{\circ} \mathrm{C}$ for $15 \mathrm{~min}$. 

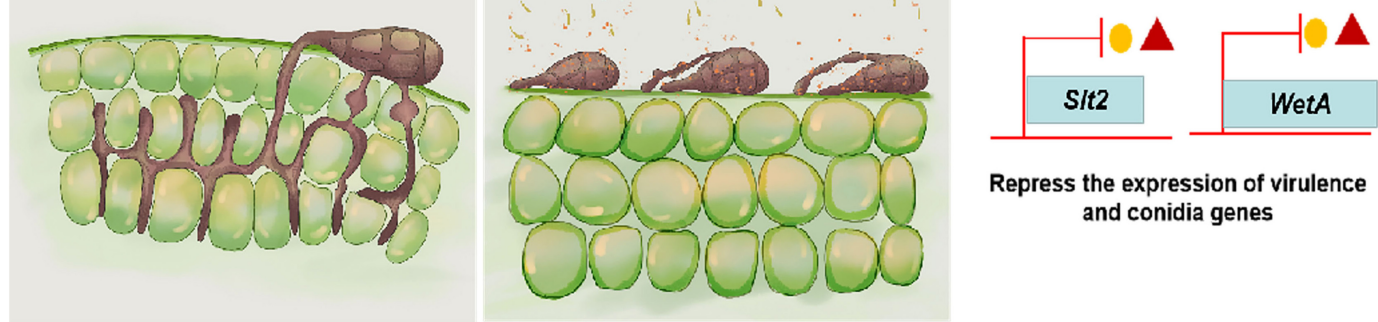

Repress the expression of virulence and conidia genes

FIGURE 6 | A model for the mode of action of 6-methyl-2-heptanone produced by ZD01 against $A$. solani. 6-Methyl-2-heptanone changes the structures of mycelia and conidia of $A$. solani, which subsequently leads to the suppression of fungal growth, mycelium penetration, conidia vitality, and germination, as well as relative virulence and conidia-related gene expression levels. As a result, $A$. solani failed to infect potato leaves.

A Thermo TSQ-8000 MS was used for peak separation and detection. The MS was operated in electron ionization mode at $70 \mathrm{eV}$ with a source temperature of $280^{\circ} \mathrm{C}$ using a continuous scan from $45 \mathrm{~m} / z$ to $450 \mathrm{~m} / z$. The ionization source and transfer line temperatures were both $230^{\circ} \mathrm{C}$, and electron ionization mode was used. The analysis was performed in full-scan mode. Mass spectral data for the volatile compounds were compared with data in the National Institute of Standards and Technology (NIST) Mass Spectrum Library. The VOCs in treated samples that were not found in the control were considered the final Bacillus-produced VOCs. The experiment was repeated three times.

For each detected peak, a standard mixture of hydrocarbons from $\mathrm{C}_{7}$ to $\mathrm{C}_{27}$ (Bailingwei Inc., Beijing, China) was prepared. The sample and the hydrocarbon standard mixture were co-injected into the GC, and the retention times were used to calculate retention indices. A linear retention index was calculated using GC retention index standards in accordance with the method of Van den Dool and Kratz (1963). The relative strength indexes of chemicals that matched chemicals in the NIST library with scores greater than 800 were used.

\section{Inhibition Assay of 6-Methyl-2-Heptanone Against A. solani in vitro}

To test the inhibition on mycelial growth, pure 6-methyl-2heptanone was purchased from Shanghai Macklin Biochemical Technology Co., Ltd. In this test, the divided plate method was used (Xie et al., 2018), and the plate allocation of the different treatments was randomized. Briefly, a 5-mm square plug from an $A$. solani mycelial agar disk was placed in one compartment of the divided plate containing PDA medium, and the other compartment containing PDA medium was incubated with different aliquots of pure compound. The doses of 6-methyl2-heptanone were $3,6,9,12$, and $15 \mu \mathrm{L}$, respectively. The dishes were immediately sealed with parafilm and incubated at $25^{\circ} \mathrm{C}$ for 4 days. Pathogens and plates not containing the pure compound were used as controls. The sample unit was represented by six replicates per dose. The inhibitory rate on mycelial growth was calculated in accordance with the following formula, and $\mathrm{EC}_{50}$ values were calculated as the effective concentrations that inhibited fungal mycelial growth by $50 \%$ in comparison with the control.

Inhibitory rate on mycelium growth $(\%)=$ (the diameter of control - the diameter of treatment group)/the diameter of control $\times 100 \%$.

The efficiency of 6-methyl-2-heptanone against A. solani conidial germination was also tested using the divided plate assay. For this purpose, $100 \mu \mathrm{L}$ of $A$. solani HWC-168 spore suspension $\left(10^{5} \mathrm{cfu} / \mathrm{mL}\right)$ was spread onto half of the $1.0 \%$ water agar medium in a divided dish, and the other side of dish was inoculated with the $\mathrm{EC}_{50}$ value of 6-methyl-2-heptanone. The spore suspension and LB plates with sterile water were used as controls. Dishes were immediately sealed with parafilm. The plates were incubated at $25^{\circ} \mathrm{C}$ for $6-8 \mathrm{~h}$, and sporulation was assessed. The experiment was repeated in triplicate.

Inhibitory rate on conidial germination $(\%)=$ (the conidial germination of control - the conidial germination of treatment group)/the conidial germination of control $\times 100 \%$.

\section{Scanning Electron Microscopy}

Scanning electron microscopy was conducted to determine the effects of 6-methyl-2-heptanone on the hyphae of A. solani at the ultra-structural level. The $A$. solani mycelia were inoculated as described in the above divided plate assay and cultured with $\mathrm{EC}_{50}$ doses of 6-methyl-2-heptanone at $25^{\circ} \mathrm{C}$ for 4 days. The plates without 6-methyl-2-heptanone were used as controls. Then, mycelia of each group were harvested and fixed in 2\% glutaraldehyde (Solarbio, Beijing, China) at $4^{\circ} \mathrm{C}$ and dehydrated with gradient ethanol solutions (50, 70, 80, 90, and 100\%) for $20 \mathrm{~min}$. Afterward, ethanol was replaced by $100 \%$ tertiary butyl ethanol. Cells were then freeze-dried, coated with gold, and imaged using a Hitachi S-3500N field emission SEM (Hitachi, Tokyo, Japan).

\section{Transmission Electron Microscopy}

Transmission electron microscopy was used to observe internal morphological changes in A. solani colonies. For groups exposed 
to pure 6-methyl-2-heptanone, the A. solani mycelia and conidia were treated with $\mathrm{E}_{C 50}$ doses of 6-methyl-2-heptanone as described in the above divided plate assay. The plates without 6-methyl-2-heptanone were used as controls. Then, hyphae and conidia were collected. For fungal deletion and WT strains, conidia were collected. The conidia were collected by centrifugation $\left(5,000 \times g\right.$ for $15 \mathrm{~min}$ at $\left.20^{\circ} \mathrm{C}\right)$. Hyphae and conidia were washed and fixed with $2 \%$ glutaraldehyde for $30 \mathrm{~min}$ at $4^{\circ} \mathrm{C}$. The specimens were prepared in accordance with Yamanaka et al. (2005) for TEM analysis. Ultra-structural changes in the cells were observed using a Hitachi H-7650 transmission electron microscope (Hitachi).

\section{Extracellular Adenosine Triphosphate Measurement Assay}

The same design as described above was used to investigate the effects of 6-methyl-2-heptanone on outer mycelial ATP contents. For A. solani, a 5-mm square plug of mycelial agar disks was placed in one compartment of the divided plate containing PDA medium, and the plate was incubated at $25^{\circ} \mathrm{C}$ for 4 days. Then, an $\mathrm{EC}_{50}$ dose of 6-methyl-2-heptanone was added to the other compartment and incubated for $0.5,1.0,1.5,2.0,2.5$, and $3.0 \mathrm{~h}$ at $25^{\circ} \mathrm{C}$. The plates without 6 -methyl-2-heptanone were used as controls. The A. solani cells and the supernatants were collected by centrifugation $\left(12,000 \times g\right.$ for $5 \mathrm{~min}$ at $\left.4^{\circ} \mathrm{C}\right)$. The extracellular ATP level was determined using an Enhanced ATP Assay Kit (Beyotime Biotechnology Inc., Shanghai, China) and a multifunction microplate reader (Tecan Spark, Salzburg, Austria). The ATP kit was based on a luminescent ATP assay protocol that involved the lysis of each cell sample and the addition of luciferase and luciferin, followed by the measurement of the emitted light. The experiment was repeated in triplicate.

\section{Fluorescence Microscopy Imaging}

For A. solani, a 5-mm square plug of a mycelial agar disk was placed in one compartment of a divided plate containing PDA medium, and the plate was incubated at $25^{\circ} \mathrm{C}$ for 4 days. One section of the cells was treated with an $\mathrm{EC}_{50}$ dose of 6methyl-2-heptanone for $6 \mathrm{~h}$ at $25^{\circ} \mathrm{C}$, and the other section was treated with sterile saline for $6 \mathrm{~h}$ at $25^{\circ} \mathrm{C}$. The mycelia were collected and re-suspended in sterile saline. Then, $0.8 \mu \mathrm{M}$ SYTOX Green solution (Invitrogen Corporation, Carlsbad, CA, United States) was added to all the cells. The samples were incubated for $15 \mathrm{~min}$ in the dark. Afterward, mycelia were rinsed two times with $8.5 \%$ sterile saline, re-suspended in sterile saline, and immediately measured for fluorescence. Green fluorescent signaling in A. solani was visualized using a Nikon Ti2-U fluorescence microscope (Nikon Corporation, Tokyo, Japan). The excitation wavelength was $488 \mathrm{~nm}$, and the emission wavelength was $538 \mathrm{~nm}$ (Mu Oz et al., 2013).

\section{Quantitative Real-Time PCR}

Total RNAs of A. solani cells co-cultured with 6-methyl-2heptanone for 2 and $6 \mathrm{~h}$ were extracted using a Bacterial RNA Kit (Omega Bio-Tek, Norcross, GA, United States) in accordance with the manufacturer's instructions. First-strand cDNA was obtained using reverse transcriptase (TransGen Biotech, Beijing, China) with random hexamer primers. Real-time PCR was performed with SYBR Premix Ex Taq ${ }^{\mathrm{TM}}$ (TransGen Biotech). The actin gene was used as an internal reference gene. The specific primers used are listed in Supplementary Table 2. The relative expression levels of specific genes were calculated using the $2^{-\Delta \Delta C T}$ method (Livak and Schmittgen, 2001).

\section{Construction of Fungal Deletion Strains}

Gene deletion vector construction and the transformation of A. solani were performed using the double-joint PCR method with minor modifications (Yu et al., 2004). The primers used for flanking sequence amplification for each gene are listed in Supplementary Table 2. A hygromycin resistance cassette replaced the open reading frame of wetA, and the constructed fragment was inserted into the pEASY-T1 cloning vector (Supplementary Table 1). After transforming the constructed plasmid into HWC-168, the subsequent deletion mutants were verified by PCR using the wetA-F/R primer set (Supplementary Table 2).

\section{In vivo Antagonistic Activity of WetA Mutants}

To determine the pathogenicity of different $A$. solani strains, $20 \mu \mathrm{L}$ of conidial suspensions $\left(10^{5} \mathrm{cfu} / \mathrm{mL}\right)$ of $\mathrm{WT}$ and wet $A$ mutants were inoculated onto the center of one piece of fresh potato leaf. After 5 days of growth under a 12-h/12-h light/dark cycle at $25^{\circ} \mathrm{C}$, the lesion diameters were measured.

\section{Statistical Analysis}

Three independent experiments were performed for each assay. Data were analyzed using SPSS 20.0 Windows Software (SPSS Inc., Chicago, IL, United States). Least significant differences were calculated to compare results at the 0.05 level.

\section{DATA AVAILABILITY STATEMENT}

The datasets presented in this study can be found in online repositories. The names of the repository/repositories and accession number(s) can be found below: https://www.ncbi.nlm. nih.gov/genbank/, CP046448.1.

\section{AUTHOR CONTRIBUTIONS}

DZ, RQ, and YF performed the experiments. DZ wrote the manuscript. JZ and JC provided data curation and methodology. DMZ provided technical assistance. DZ, ZY, and JHZ designed the experiments. ZY and JHZ provided supervision and project administration. All authors contributed to the article and approved the submitted version.

\section{FUNDING}

This work was funded by the National Natural Science Foundation of China (32001956), Research on the Cultivation 
of Innovation Ability of Postgraduate Students in Education Department of Hebei Province, China (CXZZBS2021036), China Agriculture Research System of MOF and MARA (CARS-09P18), and Modern Agro-Industry Technology Research System in Hebei Province, China (HBCT2018080205).

\section{REFERENCES}

Arrebola, E., Dharini, S., and Lise, K. (2010). Effect of volatile compounds produced by Bacillus strains on postharvest decay in citrus. Biol. Control 53, 122-128. doi: 10.1016/j.biocontrol.2009.11.010

Banani, H., Davide, S., Dianpeng, Z., Slavica, M., Garibaldi, A., and Maria, L. G. (2015). Postharvest application of a novel chitinase cloned from Metschnikowia fructicola and overexpressed in Pichia pastoris to control brown rot of peaches. Int. J. Food Microbiol. 199, 54-61. doi: 10.1016/j.ijfoodmicro.2015.01.002

Bowman, S. M., and Free, S. J. (2006). The structure and synthesis of the fungal cell wall. Bioessays 28, 799-808. doi: 10.1002/bies.20441

Calvo, H., Isabel, M., Esther, A., Ana, P., Domingo, B., and María, E. V. (2020). Antifungal activity of the volatile organic compounds produced by Bacillus velezensis strains against postharvest fungal pathogens. Postharvest Biol. Technol. 166:111208. doi: 10.1016/j.postharvbio.2020.111208

Chantal, L. M., Janette, N., Mathias, D., Robert, P., and Birgit, P. (2014). mVOC: a database of microbial volatiles. Nucleic Acids Res. 744:1016. doi: 10.1093/nar/ gkx1016

Chaves-López, C., Serio, A., Gianotti, A., Sacchetti, G., Ndagijimana, M., Ciccarone, C., et al. (2015). Diversity of food-borne Bacillus volatile compounds and influence on fungal growth. J. Appl. Microbiol. 119, 487-499. doi: 10.1111/ jam. 12847

Chaurasia, B., Pandey, A., Palni, L. M. S., Trivedi, P., Kumar, B., and Colvin, N. (2005). Diffusible and volatile compounds produced by an antagonistic Bacillus subtilis strain cause structural deformations in pathogenic fungi in vitro. Microbiol. Res. 160, 75-81. doi: 10.1016/j.micres.2004.09.013

Chen, H., Xiao, X., Wang, J., Wu, L., Zheng, Z., and Yu, Z. (2008). Antagonistic effects of volatiles generated by Bacillus subtilis on spore germination and hyphal growth of the plant pathogen, botrytis cinerea. Biotechnol. Lett. 30, 919-923. doi: 10.1007/s10529-007-9626-9

Effmert, U., Kalderás, J., Warnke, R., and Piechulla, B. (2012). Volatile mediated interactions between bacteria and fungi in the soil. J. Chem. Ecol. 38, 665-703. doi: 10.1007/s10886-012-0135-5

Gao, Z., Zhang, B., Liu, H., Han, J., and Zhang, Y. (2017). Identification of endophytic Bacillus velezensis ZSY-1 strain and antifungal activity of its volatile compounds against Alternaria solani and Botrytis cinerea. Biol. Control. 150, 27-39. doi: 10.1016/j.biocontrol.2016.11.007

Gotor-Vila, A., Teixido, N., Francesco, A. D., Usall, J., Ugolini, L., Torres, R., et al. (2017). Antifungal effect of volatile organic compounds produced by Bacillus amyloliquefaciens CPA-8 against fruit pathogen decays of cherry. Food Microbiol. 64, 219-225. doi: 10.1016/j.fm.2017.01.006

Haiyan, G., Li, P. Z., Xu, X. X., Zeng, Q., and Guan, W. Q. (2018). Research on volatile organic compounds from Bacillus subtilis CF-3: biocontrol effects on fruit fungal pathogens and dynamic changes during fermentation. Front. Microbiol. 9:456. doi: 10.3389/fmicb.2018.00456

Jiang, C. H., Liao, M. Jie, Wang, H. K., Zheng, M. Z., Xu, J. J., and Guo, J. H. (2018). Bacillus velezensis, a potential and efficient biocontrol agent in control of pepper gray mold caused by botrytis cinerea. Biol. Control 126, 147-157.

Kai, M., Haustein, M., Molina, F., Petri, A., Scholz, B., and Piechulla, B. (2009). Bacterial volatiles and their action potential. Appl. Microbio. Biotechnol. 81, 1001-1012. doi: 10.1007/s00253-008-1760-3

Khan, N., Martínez-Hidalgo, P., Ice, T. A., Maymon, M., Humm, E. A., Nejat, N., et al. (2018). Antifungal activity of bacillus species against fusarium and analysis of the potential mechanisms used in biocontrol. Front. Microbiol. 9:2363. doi: 10.3389/FMICB.2018.02363

Li, Q., Ning, P., Zheng, L., Huang, J. B., Li, G. Q., and Tom, H. (2012). Effects of volatile substances of Streptomyces globisporus JK-1 on control of Botrytis cinerea on tomato fruit. Biol. Control 61, 113-120. doi: 10.1016/j.biocontrol. 2011.10.014

\section{SUPPLEMENTARY MATERIAL}

The Supplementary Material for this article can be found online at: https://www.frontiersin.org/articles/10.3389/fmicb. 2021.808337/full\#supplementary-material

Li, Z., Situ, J. J., Zhu, Q. F., Xi, P. G., Zheng, Y., Liu, H. X., et al. (2019). Identifification of volatile organic compounds for the biocontrol of postharvest litchi fruit pathogen Peronophythora litchii. Postharvest Biol. Technol. 155, 37-46. doi: 10.1016/j.postharvbio.2019.05.009

Liu, C., Yin, X. H., Wang, Q. G., Peng, Y., Ma, Y. R., Liu, P., et al. (2018). Antagonistic activities of volatiles produced by two Bacillus strains against monilinia fructicola in peach fruit. J. Sci. Food Agric. 98, 5756-5763. doi: 10. 1002 /jsfa.9125

Livak, K. J., and Schmittgen, T. D. (2001). Analysis of relative gene expression data using real-time quantitative PCR and the 2- $\triangle \mathrm{CT}$ method. Methods 25, 402-408. doi: 10.1006/meth.2001.1262

Maachia, B., Rafik, E., Chérif, M., Nandal, P., and Bernard, P. (2015). Biological control of the grapevine diseases 'grey mold' and 'powdery mildew' by Bacillus B27 and B29 strains. Indian J. Exp. Biol. 53, 109-115.

Marshall, M. A., and Timberlake, W. E. (1991). Aspergillus nidulans wetA activates spore-specific gene expression. Mol. Cell. Biol. 11, 55-62. doi: 10.1128/mcb.11. $1.55-62.1991$

Martins, S. J., de Faria, A. F., Pedroso, M. P., Cunha, M. G., da Rocha, M. R., and de Medeiros, F. H. V. (2019). Microbial volatiles organic compounds control anthracnose (Colletotrichum lindemuthianum) in common bean (Phaseolus vulgaris L.). Biol. Control. 131, 36-42. doi: 10.1016/j.biocontrol.2019.01.003

Massawe, V. C., Rao, A. H., Farzand, A., Mburu, D. K., and Gao, X. (2018). Volatile organic compounds of endophytic bacillus spp. have biocontrol activity against sclerotinia sclerotiorum. Phytopathology 108, 1373-1385. doi: 10.1094/ PHYTO-04-18-0118-R

Morath, S. U., Hung, R., and Bennett, J. W. (2012). Fungal volatile organic compounds: a review with emphasis on their biotechnological potential. Fungal Biol. Rev. 26, 73-83. doi: 10.1016/j.fbr.2012.07.001

Morgan, G. D., Stevenson, W. R., Macguidwin, A. E., Kelling, K. A., and Zhu, J. (2002). Plant pathogen population dynamics in potato fields. J. Nematol. 34, 189-193.

Mu Oz, A., Gandía, M., Harries, E., Carmona, L., Read, N. D., and Marcos, J. F. (2013). Understanding the mechanism of action of cell-penetrating antifungal peptides using the rationally designed hexapeptide PAF26 as a model. Fungal Biol. Rev. 26, 146-155. doi: 10.1016/j.fbr.2012.10.003

Pasche, J. S., Wharam, C. M., and Gudmestad, N. C. (2007). Shift in sensitivity of alternaria solani in response to Q o I fungicides. Plant Dis. 88, 181-187. doi: 10.1094/PDIS.2004.88.2.181

Peters, R. D., Drake, K. A., Gudmestad, N. C., Pasche, J. S., and Shinners-Carnelley, T. (2008). First report of reduced sensitivity to a QoI fungicide in isolates of alternaria solani causing early blight of potato in Canada. Plant Dis. 92, 1707-1707. doi: 10.1094/PDIS-92-12-1707B

Raza, W., Ling, N., Yang, L., Huang, Q., and Shen, Q. (2016a). Response of tomato wilt pathogen Ralstonia solanacearum to the volatile organic compounds produced by a biocontrol strain Bacillus amyloliquefaciens SQR-9. Sci. Rep. 6:24856. doi: 10.1038/srep24856

Raza, W., Wang, J., Wu, Y., Ling, N., Wei, Z., Huang, Q., et al. (2016b). Effects of volatile organic compounds produced by Bacillus amyloliquefaciens on the growth and virulence traits of tomato bacterial wilt pathogen Ralstonia solanacearum. Appl. Microbiol. Biotechnol. 100, 7639-7650. doi: 10.1007/ s00253-016-7584-7

Raza, W., Yuan, J., Ling, N., Huang, Q., and Shen, Q. (2015). Production of volatile organic compounds by an antagonistic strain Paenibacillus polymyxa WR-2 in the presence of root exudates and organic fertilizer and their antifungal activity against Fusarium oxysporum f. sp. niveum. Biol. Control 80, 89-95. doi: 10.1016/j.biocontrol.2014.09.004

Ruiz-Herrera, J., Elorza, M. V., Valentín, E., and Sentandreu, R. (2006). Molecular organization of the cell wall of Candida albicans and its relation to pathogenicity. FEMS Yeast Res. 6, 14-29. doi: 10.1111/j.1567-1364.2005. 00017.x 
Schreinemachers, P., and Tipraqsa. (2012). Agricultural pesticides and land use intensification in high, middle and low income countries. Food Policy 6, 616-626. doi: 10.1016/j.foodpol.2012.06.003

Senthil, R., Prabakar, K., Rajendran, L., and Karthikeyan, G. (2011). Efficacy of different biological control agents against major postharvest pathogens of grapes under room temperature storage conditions. Phytopathol. Mediterranea 50, 55-65.

Sewall, T. C., Mims, C. W., and Timberlake, W. E. (1990). Conidium differentiation in Aspergillus nidulans wild-type and wet-white (wetA) mutant strains. Developmental Biology. 138, 499-508. doi: 10.1016/0012-1606(90)90215-5

Shao, X., Cheng, S., Wang, H., Yu, D., and Mungai, C. (2013). The possible mechanism of antifungal action of tea tree oil on Botrytis cinerea. J. Appl. Microbiol. 114, 1642-1649. doi: 10.1111/jam.12193

Tao, N., OuYang, Q., and Jia, L. (2014). Citral inhibits mycelial growth of Penicillium italicum by a membrane damage mechanism. Food Control 41, 116-121. doi: 10.1016/j.foodcont.2014.01.010

Tran, T. D., Del, C. C., Hnasko, R., Gorski, L., and McGarvey, J. A. (2020). Bacillus amyloliquefaciens ALB65 inhibits the growth of listeria monocytogenes on cantaloupe melons. Appl. Environ. Microbiol. 87:e01926-20. doi: 10.1128/AEM. 01926- 20

Van den Dool, H., and Kratz, P. (1963). A generalization of the retention index system including linear temperature programmed gasliquid partition chromatography. J. Chromatogr. 11, 463-471. doi: 10.1016/s0021-9673(01) 80947-x

Wang, C. J., and Liu, Z. Q. (2007). Foliar uptake of pesticides-present status and future challenge. Pesticide Biochem. Physiol. 87, 1-8. doi: 10.1016/j.pestbp.2006. 04.004

Wichitra, L., Punpen, H., and Samerchai, C. (2008). Growth inhibitory properties of Bacillus subtilis strains and their metabolites against the green mold pathogen (Penicillium digitatum Sacc.) of citrus fruit. Postharvest Biol. Technol. 48, 113-121. doi: 10.1016/j.postharvbio.2007.09.024

Wu, Y. C., Zhou, J. Y., Li, C. G., and Yan, M. (2019). Antifungal and plant growth promotion activity of volatile organic compounds produced by Bacillus amyloliquefaciens. Microbiol.Open 8:813. doi: 10.1002/ mbo3.813

Xie, S., Zang, H., Wu, H., Uddin, R. F., and Gao, X. (2018). Antibacterial effects of volatiles produced by Bacillus strain D13 against Xanthomonas oryzae pv. oryzae. Mol Plant Pathol. 19, 49-58. doi: 10.1111/mpp.12494

Yamanaka, M., Hara, K., and Kudo, J. (2005). Bactericidal actions of a silver ion solution on Escherichia coli, studied by energy-filtering transmission electron microscopy and proteomic analysis. Appl. Environ. Microbiol. 71, 7589-7593. doi: 10.1128/AEM.71.11.7589-7593.2005
Yu, J. H., Hamari, Z., Han, K. H., Seo, J. A., Reyes-Domínguez, Y., and Scazzocchio, C. (2004). Double-joint PCR: a PCR-based molecular tool for gene manipulations in fifilamentous fungi. Fungal Genet. Biol. 41, 973-981. doi: 10.1016/j.fgb.2004.08.001

Zhang, D., He, J. Y., Haddadi, P., Zhu, J. H., Yang, Z. H., and Ma, L. S. (2018). Genome sequence of the potato pathogenic fungus Alternaria solani HWC168 reveals clues for its conidiation and virulence. BioMed Central 18:176. doi: 10.1186/s12866-018-1324-3

Zhang, D., Yu, S. Q., Yang, Y. Q., Zhang, J. L., and Zhu, J. H. (2020). Antifungal effects of volatiles produced by bacillus subtilis against alternaria solani in potato. Frontiers in Microbiology. 11:1196. doi: 10.3389/FMICB.2020. 01196

Zhang, D., Yu, S. Q., Zhao, D. M., Zhang, J. L., Pan, Y., Yang, Y. Q., et al. (2021). Inhibitory effects of non-volatiles lipopeptides and volatiles ketones metabolites secreted by Bacillus velezensis C16 against Alternaria solani. Biol. Control 152:104421. doi: 10.1016/J.BIOCONTROL.2020.104421

Zhang, X. Y., Gao, Z. F., Zhang, X. X., Bai, W. B., Zhang, L. X., and Pei, H. B. (2020). Control effects of Bacillus siamensis G-3 volatile compounds on raspberry postharvest diseases caused by Botrytis cinerea and Rhizopus stolonifer. Biol. Control 141:104135. doi: 10.1016/j.biocontrol.2019.104135

Zheng, M., Shi, J. Y., Shi, J., Wang, Q., and Li, Y. (2013). Antimicrobial effects of volatiles produced by two antagonistic Bacillus strains on the anthracnose pathogen in postharvest mangos. Biol. Control 65, 200-206. doi: 10.1016/j. biocontrol.2013.02.004

Conflict of Interest: The authors declare that the research was conducted in the absence of any commercial or financial relationships that could be construed as a potential conflict of interest.

Publisher's Note: All claims expressed in this article are solely those of the authors and do not necessarily represent those of their affiliated organizations, or those of the publisher, the editors and the reviewers. Any product that may be evaluated in this article, or claim that may be made by its manufacturer, is not guaranteed or endorsed by the publisher.

Copyright (c) 2022 Zhang, Qiang, Zhao, Zhang, Cheng, Zhao, Fan, Yang and Zhu. This is an open-access article distributed under the terms of the Creative Commons Attribution License (CC BY). The use, distribution or reproduction in other forums is permitted, provided the original author(s) and the copyright owner(s) are credited and that the original publication in this journal is cited, in accordance with accepted academic practice. No use, distribution or reproduction is permitted which does not comply with these terms. 